\title{
WHAT GROUPS WERE: A STUDY OF THE DEVELOPMENT OF THE AXIOMATICS OF GROUP THEORY
}

\author{
Peter M. NeumanN
}

\section{For my father for his ninetieth birthday: 15 October 1999}

\begin{abstract}
This paper is devoted to a historical study of axioms for group theory. It begins with the emergence of groups in the work of Galois and Cauchy, treats two lines of development discernible in the latter half of the nineteenth century, and concludes with a note about some twentieth century ideas. One of those nineteenth century lines involved Cayley, Dyck and Burnside; the other involved Kronecker, Weber (very strongly), Hölder and Frobenius.
\end{abstract}

\section{INTRODUCTION}

As is well known, my father has long had an interest in axiomatics, especially the axiomatics of group theory (see, for example, $[\mathbf{2 1}, \mathbf{3 4}, \mathbf{3 5}]$ ). My purpose in this essay is to trace the origins and development of currently familiar axiom systems for groups. A far more general study of the origins of the concept of abstract group has been undertaken by Wussing (see [42, Chapter 3, Section 4]) who, however, treats the axiomatics rather differently. George Abram Miller has also written on the subject but perhaps a little erratically. Statements like

It should perhaps be noted in this connection that an abstract goup is a set of distinct elements which obey the associative law when they are combined and is closed with respect to the unique solutions of linear equations in the special form $a x=b$. This special form appears already in the Rhind Mathematical Papyrus. [31, p.97 (1935).]

are not easy to make sense of. On the other hand, his observations:

During recent years accurate definitions of an abstract group have been formulated. These are principally due to Frobenius and Weber. Such definitions are stated at the beginning of the second volume of Weber's Algebra. It is to be hoped that practical uniformity in regard to the definition of an

Received 27th May, 1999

Copyright Clearance Centre, Inc. Serial-fee code: 0004-9727/99 \$A2.00+0.00. 
abstract group may be attained [ ... ] the term abstract group is frequently defined very inadequately, even in recent works, [ .. ]. [31, p.339 (1899).]

and

Men like S. Lie (1842-1899) and F. Klein (1849-1925) continued to use the term group without defining it except that they assumed that the product of two elements of a given group is contained therein and sometimes they assumed also the existence of the inverse of every element within the group. $[31$, p.96 (1935).]

and

H. Weber (1842-1913) published a set of postulates for abstract groups of finite order in the Mathematische Annalen, volume 20 (1882), page 302, which were extensively adopted by later writers in various countries. [31, p.453 (1935).]

can be substantially justified.

Teachers and students are often heard to refer to 'the four axioms of group theory'. The conventional reference is to Closure, Associativity, existence of an Identity element, and existence of Inverses. And the capitalised nouns in this last sentence are sometimes used as labels for them. Thus, for example, a well-known (and very successful) presentation of the theory defines a binary operation as 'a means of combining two elements' and defines $(G, \circ)$, where $G$ is a set and o is a binary operation defined on $G$, to be a group if the following four conditions hold.

CLOSURE For all $g_{1}, g_{2} \in G, g_{1} \circ g_{2} \in G$.

IDENTITY There exists $e \in G$ such that for all $g \in G, g \circ e=e \circ g=g$.

INVERSES For each $g \in G$ there exists $g^{-1} \in G$ such that $g \circ g^{-1}=g^{-1} \circ g=e$.

ASSOCIATIVITY For all $g_{1}, g_{2}, g_{3} \in G, g_{1} \circ\left(g_{2} \circ g_{3}\right)=\left(g_{1} \circ g_{2}\right) \circ g_{3}$.

Although this definition is tried and tested and is successful pedagogically (as are many others like it), I myself do not feel comfortable with it. If a means of combining two elements of the set $G$, or a binary operation on the set $G$, is not a function $G \times G \rightarrow G$ then what is it? And if it is, then what is the point of the axiom of Closure? In the Inverses axiom, what is the element $e$ ? Of course it should be the same $e$ as was postulated in the Identity axiom. But in that statement $e$ is, technically, a bound variable and has no value outside the sentence. By analogy, if I use $G$ to stand for a group in one paper, I can still use it to stand for something quite different, such as the 
gravitational constant, in another. If we were to change $e$ to $f$ in the Identity axiom it would still be perfectly acceptable - indeed, its meaning would be quite unchanged—and yet the Inverse axiom would no longer make sense. Thus in fact Identity and Inverse need to be combined in such a way that the scope of the existentional quantifier $\exists e$ covers both. Well, this exemplifies the fact that the needs of pedagogy are not always easy to accommodate to the precision of mathematics - or vice-versa. That, however, is the subject of a different essay. For the purposes of this one we may take Closure to be the definition of a binary operation or to be a conventional textbook version of it, and we will take the scope of the quantifier $\exists e$ in the Identity axiom to include the Inverses axiom.

Group theory as we have it nowadays took a long time to evolve. It emerged around the middle of the nineteenth century from work of Galois published in 1846 (but written between 1829 and 1832) and work of Cauchy published the previous year. Cauchy's line of thinking can be traced still further back, to work of Ruffini published between 1799 and 1814. Ruffini's ideas have been analysed by various authors (for example $[3,4,7]$ ). Since he seems not to have had much direct influence on his successors, except a little tangentially through inspiring Cauchy to study substitutions in 1812 (this work was published in 1815), the present paper begins with Galois and Cauchy.

\section{Galois and CAUChY}

Although there is plenty about groups in the writings of Galois, particularly in the so-called Second Mémoire [20, pp.129-147], the reader is given little direct guidance as to what a group is supposed to be. The context gives the information indirectly but the only explicit help that Galois gives his reader is in the Premier Mémoire [20, p.47]:

Les substitutions sont le passage d'une permutation à l'autre.

$[\ldots]$

Cependant comme on ne peut guère se former l'idée d'une substitution sans celle d'une permutation, nous ferons dans le langage un emploi fréquent des permutations, et nous ne considérerons les substitutions que comme le passage d'une permutation à une autre.

[...]

Comme il s'agit toujours de questions où la disposition primitive des lettres n'influe en rien, dans les groupes que nous considérerons, on devra avoir les mêmes substitutions quelle que soit la permutation d'où l'on sera parti. Donc si dans un pareil groupe on a les substitutions $S$ et $T$, on est sûr d'avoir la substitution $S T$.

This passage was added to the manuscript on the night of the 29th of May 1832, the 
night that Galois edited his papers and wrote his testamentary letter to Chevalier before going out to duel in the morning. It was not there in 1831, and when Poisson read the work for the Academy he had to work out for himself what Galois intended when he used the word 'groupe'. Its last sentence contains the crucial fact that a group of substitutions has to be closed under composition, a requirement which is, of course, an adequate definition in this context (given the presupposition that the collection of substitutions is non-empty and finite). Note that Galois distinguished carefully between permutations and substitutions. As it happens, he used the word 'groupe' with two different connotations. First, it is a collection of permutations (in the sense of arrangements). Secondly, it is, as is indicated in the quoted passage, the group of substitutions by which one passes from one permutation of the collection to another. For an account of this point the reader is referred to [16, Appendix 3].

Cauchy's definition and terminology are somewhat different. He came to the concept from a different direction and it is almost certain that he came to it independently of Galois. Unfortunately, we cannot be completely sure since he had some of Galois' work in his hands in 1829 (see [39]; see also Procès-Verbaux de l'Acad. Sci., Vol 9 (1828-31), pp.253, 257). In 1845 he wrote [8, p.290 in the Euvres]:

Considérons maintenant plusieurs substitutions

$$
\left(\begin{array}{l}
B \\
A
\end{array}\right), \quad\left(\begin{array}{l}
D \\
C
\end{array}\right), \quad\left(\begin{array}{l}
F \\
E
\end{array}\right), \quad \ldots
$$

relatives aux $n$ lettres $x, y, z, \ldots$ J'appellerai substitutions dérivées toutes celles que l'on pourra déduire des substitutions données, multipliées une ou plusieurs fois les unes par les autres ou par elles-mêmes dans un ordre quelconque, et les substitutions données, jointes aux substitutions dérivées, formeront ce que j'appellerai un système de substitutions conjuguées.

This same passage appears in [9, p.206 in the Euvres] except that the first two sentences are merged to form a single sentence beginning 'Étant données une ou plusieurs substitutions qui renferme les $n$ lettres $x, y, z, \ldots$, ou du moins plusieurs d'entre elles, je nommerai substitutions dérivées [...]'.

Although this is less efficient than simply postulating a (non-empty) collection of substitutions closed under composition, it comes to the same thing. And Cauchy went on to point out a few paragraphs later that a 'système de substitutions conjuguées' has the property that if its members are composed on either side by a given member then the system is reproduced (perhaps in a different order). And when, in 1866, Cauchy's ideas on substitutions made it into the third edition of Serret's textbook [38, Vol.2, p.251], the definition became, modulo verbosity, the same as that of Galois. 
The ideas of Galois were re-worked and transmitted by several mathematicians until they received remarkably thorough treatment at the hand of Jordan, whose Traité is modestly described by its author as being hardly more than a commentary on Galois [25, Préface, p.viii]. Jordan had learned the theory of 'systèmes de substitutions conjuguées' from Bertrand, and used Cauchy's language in his early work (1861), but by 1864 (see the first few papers in [26, Vol.I]) he was using Galois' word 'groupe', and in spite of the influence of Serret's book, Cauchy's phrase soon died out. In this line of work, however, groups remained groups of substitutions for many more years. Jordan, for example, never seems to have become comfortable with abstract groups at all. And when Klein spoke and wrote about groups in his Erlanger Programm, which was published privately in 1872 and re-published in Mathematische Annalen in 1893, they were concretely described as groups of transformations of space [27].

\section{Cayley, Dyck and Burnside}

An early and famous attempt at axiomatisation of group theory was made by Cayley in 1854. His paper [10] opens

Let $\theta$ be a symbol of operation, which may, if we please, have for its operand, not a single quantity $x$, but a system $(x, y, \ldots)$, so that

$$
\theta(x, y, \ldots)=\left(x^{\prime}, y^{\prime}, \ldots\right)
$$

where $x^{\prime}, y^{\prime}, \ldots$ are any functions whatever of $x, y, \ldots$, it is not even necessary that $x^{\prime}, y^{\prime}, \ldots$ should be the same in number with $x$, $y, \ldots[\quad[\ldots]$ the symbol 1 will naturally denote an operation which $[\ldots]$ leaves the operand unaltered [ ... ]. A symbol $\theta \phi$ denotes the compound operation, the performance of which is equivalent to the performance, first of the operation $\phi$, and then of the operation $\theta ; \theta \phi$ is of course in general different from $\phi \theta$. But the symbols $\theta, \phi, \ldots$ are in general such that $\theta . \phi \chi=\theta \phi . \chi, \& c .$, so that $\theta \phi \chi, \theta \phi \chi \omega$, \&c. have a definite signification independent of the particular mode of compounding the symbols; [ .. ].

A set of symbols,

$$
1, \alpha, \beta, \ldots
$$

all of them different, and such that the product of any two of them (no matter in what order), or the product of any one of them into itself, belongs to the set, is said to be a group.

There is a footnote marker attached to the italicised word group: 'The idea of a group as applied to permutations or substitutions is due to Galois, and the introduction of 
it may be considered as marking an epoch in the progress of the theory of algebraical equations'.

What should we make of Cayley's definition? On the one hand it can easily be criticised. If the 'symbols of operation' really are operations, as they appear to be since Cayley speaks of 'the compound operation' and 'performance' of an operation, then this is hardly more general than what Galois and Cauchy had in mind. It is true that the system of operands could be infinite, but in that case inverses cannot be inferred and have to be postulated; besides, from the context it seems that Cayley had a finite set in mind. Even if the system of operands is finite it is not clear how 'the compound operation' is to be defined nor how inverses can exist if there is freedom to permit $x^{\prime}$, $y^{\prime}, \ldots$ to be different in number from the original operands. Again, if the 'symbols of operation' really are operations then associativity is automatic and does not need to be postulated. And indeed, when he reproduced his definition with surprisingly little change twice in 1878, he wrote in [11] (which is datelined Cambridge, 26th November, 1877) though not in [12] (which was 'read' by the London Mathematical Society May $9,1878)$ :

The associativeness of such symbols arises from the circumstance that the definitions of $\alpha, \beta, \gamma, \ldots$ determine the meanings of $\alpha \beta, \alpha \gamma, \& \mathrm{c}$.

On the other hand, Cayley's text focusses attention on the importance of the associative law. Moreover, the assertion [11, 12] 'A group is defined by means of the laws of combination of its symbols' seems to have caught the imagination of several mathematicians in the next few decades.

One of the mathematicians whose eye was caught by Cayley's phrase was Dyck who quoted it as a sort of motto at the head of his paper [14]. This work begins as follows (the italics are Dyck's):

Die folgenden Untersuchungen beschäftigen sich mit dem Probleme, eine Gruppe von discreten Operationen, welche auf ein gewisses Object angewandt werden, zu definiren, wenn man dabei von einer speciellen Darstellungsform der einzelnen Operationen absieht, diese vielmehr nur nach den zur Gruppenbildung wesentlichen Eigenschaften als gegeben voraussetzt.

Wir gehen zur Bildung der Gruppe von gewissen erzeugenden Operationen $A_{1}, A_{2}, A_{3}, \ldots$ aus, über deren speciellen Charakter keinerlei Annahmen gemacht werden.

Dann kann man jede Gruppe, welche durch Iteration und Combination dieser Operationen sich bilden lässt, individualisiren, durch die Kenntniss gewisser Relationen, die bei der Zusammensetzung dieser ursprünglichen $O p$ erationen auftreten. 
This definition is amplified and completed in the main part of the paper immediately following the four-page introduction. Existence of identity and existence of inverses are explicitly stated. Associativity is not mentioned but is implicit in the statement that elements of the group can be expressed as formal or symbolic products $A_{1}^{\mu_{1}} A_{2}^{\mu_{2}} \cdots A_{1}^{\nu_{1}} A_{2}^{\nu_{2}} \cdots$. A very similar definition is rehearsed in the sequel [15].

There are several interesting points about Dyck's description of what a group is. One is that for Dyck a group is described by generators and relations. Another is that (unlike several later writers) he is quite clear that a group could be infinite:

Dabei kann die so bestimmte Gruppe eine endliche, oder auch eine unendlich hohe $\mathrm{Zahl}$ von Operationen umfassen. [15, p.74.]

Presentation by generators and relations is particularly well-adapted to accommodate this possibility, although from a modern point of view it has the disadvantage that it does not naturally accommodate uncountable groups (unless notation like $A_{1}, A_{2}, A_{3}$, $\ldots$ is interpreted rather freely). A third notable point is that a footnote attached to the third paragraph of the opening passage of [14] refers to the quotation from Cayley and suggests that this is what he takes Cayley to mean. What an interesting interpretation of Cayley's words!

In the preface to his monograph of 1897 , Burnside also quoted those words, referring to them as 'Cayley's dictum'. Moreover, some of the language he used is similar to Cayley's. Thus both editions of his book [6] begin Chapter II with the following definition:

Definition. Let

$$
A, B, C, \ldots
$$

represent a set of operations, which can be performed on the same object or set of objects. Suppose this set of operations has the following characteristics.

$(\alpha)$ The operations of the set are all distinct, so that no two of them produce the same change in every possible application.

$(\beta)$ The result of performing successively any number of operations of the set, say $A, B, \ldots, K$, is another definite operation of the set, which depends only on the component operations and the sequence in which they are carried out, and not on the way in which they may be regarded as associated. Thus $A$ followed by $B$ and $B$ followed by $C$ are operations of the set, say $D$ and $E$; and $D$ followed by $C$ is the same operation as $A$ followed by $E$.

( $\gamma$ ) $A$ being any operation of the set, there is always another operation $A_{-1}$ belonging to the set, such that $A$ followed by $A_{-1}$ produces no change in any object. The operation $A_{-1}$ is called the inverse of $A$. 
The set of operations is then said to form a Group.

As I have commented elsewhere [36], most of Burnside's writing is very taut: this definition, by contrast, seems uncharacteristically flabby. Condition $(\beta)$ postulates closure and the associative law, but if the associative law is not automatic, then what can he mean by 'operations' and by 'performing successively'? In the presence of closure $(\gamma)$ implies that 'no change' is an operation of the set, and of course 'no change' certainly is a two-sided identity for operations if that word has its natural meaning. If, in an attempt to discover whether Burnside's definition really is more general than it looks at first sight, we seek to replace the word 'operation' by some noun that carries fewer overtones, such as 'element', then $(\beta)$ would have to be interpreted as introducing a binary operation ('performing successively') which is associative and $(\gamma)$ would have to be interpreted as introducing a two-sided identity ('no change') and right inverses. But what about $(\alpha)$ ? Its second half would have to be deleted, and the status of its first half would remain just as unclear as before-its effect is perhaps no more than to distinguish sets from multisets.

These points are similar to, if not quite the same as, some of the criticisms that can be made of Cayley's definitions of 1854 and 1878. We can infer from Burnside's use of language and his reference to 'Cayley's dictum' that he was strongly influenced by Cayley. On the other hand, his explicit statement about inverses represents significant progress. Possibly in this he was influenced by Dyck. If so then we might ask why he was not also influenced by the German writers to be discussed in the next section. By 1897 when he wrote his book he had certainly read Frobenius's paper [17] (see the acknowledgement in [5, p.192]); he was also in correspondence with Hölder and had read Hölder's papers. Certainly, therefore, he had been exposed to the clean-cut axiomatisation that was developing from Weber's ideas (see the next section). Moreover, in his preface [6, p.vi] he acknowledged Weber's Lehrbuch in the following words:

Last but not least among the works which give a detailed account of the subject must be mentioned Herr Weber's "Lehrbuch der Algebra," of which the first volume appeared in 1895 and the second in 1896. In the last section of the first volume some of the more important properties of substitution groups are given. In the first section of the second volume, however, the subject is approached from a more general point of view, and a theory of finite groups is developed which is quite independent of any special mode of representing them.

I find it surprising that he did not recognise the merits of Weber's (see below) over his own choice of definition. Perhaps this is a sign that he was rather more comfortable with transformation groups of one kind or another than with abstract groups. Perhaps 
also that he cared more about the deep theorems of his subject than about the precise foundations. And the fact is that, well-expressed or (as I think) not, Burnside's definition does have the essential ingredients - an associative binary operation and inverses explicitly stipulated.

\section{Kronecker, Weber, FrobeniUs, Hölder}

The value of abstract group theory had been emerging during the last two decades of the nineteenth century. Partly it entered mathematics to accommodate the fact that structures with analogous properties to finite groups of substitutions had been found to be important in geometry, number theory and analysis. Partly it arose from the need for quotient groups and the fact that they do not exist very comfortably in the category of permutation groups. Although Burnside, like Jordan before him, does not seem to have felt any need to replace his internal understanding of groups as being composed of 'operations' (not always, but often, permutations) with anything more genuinely abstract. in Germany much clearer formulations had already been developed by the time he wrote his monograph.

The beginnings of modern-style axiomatics of group theory can be traced as far back as a paper by Kronecker published in 1870. Kronecker's context is commutative groups because he is setting up what we now call the class-group of an algebraic number field [28]:

Es seien

$$
\theta^{\prime}, \theta^{\prime \prime}, \theta^{\prime \prime \prime}, \ldots
$$

Elemente in endlicher Anzahl und so beschaffen, dass sich aus je zweien derselben mittels eines bestimmten Verfahrens ein drittes ableiten lässt. Demnach soll, wenn das Resultat dieses Verfahrens durch $f$ angedeutet wird, für zwei beliebige Elemente $\theta^{\prime}$ und $\theta^{\prime \prime}$, welche auch mit einander identisch sein können, ein $\theta^{\prime \prime \prime}$ existiren, welches gleich: $\mathfrak{f}\left(\theta^{\prime}, \theta^{\prime \prime}\right)$ ist. Ueberdies soll:

$$
\begin{aligned}
\mathfrak{f}\left(\theta^{\prime}, \theta^{\prime \prime}\right) & =\mathfrak{f}\left(\theta^{\prime \prime}, \theta^{\prime}\right) \\
\mathfrak{f}\left(\theta^{\prime}, \mathfrak{f}\left(\theta^{\prime \prime}, \theta^{\prime \prime \prime}\right)\right) & =\mathfrak{f}\left(\mathfrak{f}\left(\theta^{\prime}, \theta^{\prime \prime}\right), \theta^{\prime \prime \prime}\right)
\end{aligned}
$$

und aber, sobald $\theta^{\prime \prime}$ und $\theta^{\prime \prime \prime}$ von einander verschieden sind, auch:

$$
f\left(\theta^{\prime}, \theta^{\prime \prime}\right) \text { nicht identisch mit } \mathfrak{f}\left(\theta^{\prime}, \theta^{\prime \prime \prime}\right)
$$

sein.

Note that Kronecker did not use any such word as 'Gruppe'. His elements are completely general, his binary operation is explicit and general, his statement of the associative 
law is clear, so is his cancellation axiom. What he defined was what we would now call a finite (commutative) cancellative semigroup.

A similar definition, explicitly about groups and without the commutativity, was made twelve years later by Weber. Although he was familiar with Kronecker's work, there is no reference to [28] in [40] and, since the language and notation he used are very different from Kronecker's, it is probably safe to assume that there was little or no direct influence. Section 1 of his paper [40] is entitled 'Hülfssätze über Gruppen' and begins:

Definition. Ein System $G$ von $h$ Elementen irgend welcher Art, $\Theta_{1}, \Theta_{2}$, $\ldots, \Theta_{h}$ heisst eine Gruppe vom Grade $h$, wenn es den folgenden Bedingungen genügt:

I. Durch irgend eine Vorschrift, welche als Composition oder Multiplication bezeichnet wird, leitet man aus zwei Elementen des Systems ein neues Element desselben Systems her. In Zeichen

$$
\Theta_{r} \Theta_{s}=\Theta_{t}
$$

II. Es ist stets

$$
\left(\Theta_{r} \Theta_{s}\right) \Theta_{t}=\Theta_{r}\left(\Theta_{s} \Theta_{t}\right)=\Theta_{r} \Theta_{s} \Theta_{t}
$$

III. Aus $\Theta \Theta_{r}=\Theta \Theta_{s}$ und aus $\Theta_{r} \Theta=\Theta_{s} \Theta$ folgt $\Theta_{r}=\Theta_{s}$.

Here we see connections with the group theory of Galois (and Cauchy), Jordan, Cayley through the use of the term 'Gruppe' and the possibility of non-commutativity. Finiteness is still an important ingredient, however, and is used in the immediately following paragraphs to infer the existence and uniqueness of identity and inverses. Thus for Weber a group is what we would now call a finite cancellative semigroup. His definition is economical and very clear, except in one small respect: the status of the assertion $=\Theta_{r} \Theta_{s} \Theta_{t}$ in Axiom II is doubtful. Unless we take it as definition of the three-factor product, it seems to have no meaning. But this is a small point. By the standards of the time it would not have distracted readers from the point Weber was seeking to make. And the fact is that Weber's definition was often referred to by later writers.

The famous paper of Frobenius and Stickelberger [18], which was published three years before Weber's, is about commutative groups and uses the term 'Gruppe' extensively. Connection with groups in the sense of groups of substitutions is made by a passing reference in Section 1 to Cauchy [9]. Nevertheless, although the aim is to explain and prove the structure theorem for finite Abelian groups in general, the meaning of the word is explained rather discursively, essentially in terms of examples from 
number theory. On the other hand, when Frobenius was writing in 1884 (published as [17]) he referred to Kronecker [28] and to Weber [40] and defined what he meant by a (finite) group very precisely, rehearsing essentially Weber's definition.

Hölder, in his paper [22] of 1889, treats the matter similarly. Although the elements of his groups are called 'Operationen' and although the paper refers to Dyck repeatedly and never to Weber, he was, I believe, strongly influenced by the latter. Indeed, if the word 'Operation' is replaced by 'Element' then his definition still makes excellent sense and becomes essentially the same as Weber's, namely that of a finite cancellative semigroup.

The next step in the development was again taken by Weber. The opening section of the second volume of his Lehrbuch [41] has the heading 'Definition der Gruppen' and begins as follows:

\section{DEFINITION DER GRUPPEN}

Wir haben im ersten Bande bei den Permutationen den Begriff einer Gruppe kennen gelernt und wichtige algebraische Anwendungen von ihm gemacht. Es muss nun unsere nächste Aufgabe sein, diesen in der ganzen neueren Mathematik so überaus wichtigen Begriff allgemeiner zu fassen und die dabei herrschenden Gesetze kennen zu lernen. Wir stellen folgende Definition an die Spitze:

Ein System $P$ von Dingen (Elementen) irgend welcher Art wird zur Gruppe, wenn folgende Voraussetzungen erfüllt sind:

1. Es ist eine Vorschrift gegeben, nach der aus einem ersten und einem zweiten Elemente des Systems ein ganz bestimmtes drittes Element desselben Systems abgeleitet wird.

Man schreibt symbolisch, wenn $a$ das erste, $b$ das zweite, $c$ das dritte Element ist:

$$
a b=c, \quad c=a b,
$$

$[\ldots]$

Bei dieser Composition wird im Allgemeinen nicht das commutative Gesetz vorausgesetzt, d. h. es kann $a b$ von $b a$ verschieden sein, dagegen wird

2. das associative Gesetz vorausgesetzt,

d. h. wenn $a, b, c$ irgend drei Elemente aus $P$ sind, so ist

$$
(a b) c=a(b c)
$$

$[\ldots]$ 
3. Es wird vorausgesetzt, dass, wenn $a b=a b^{\prime}$ oder $a b=a^{\prime} b$ ist, nothwendig im ersten Falle $b=b^{\prime}$, im zweiten $a=a^{\prime}$ sein muss.

Wenn $P$ eine endliche Anzahl von Elementen umfasst, so heisst die Gruppe eine endliche und die Anzahl ihrer Elemente ihr Grad.

Für endliche Gruppen ergiebt sich aus 1., 2., 3. die Folgerung:

4. Wenn von den drei Elementen $a, b, c$ aus $P$ zwei beliebig gegeben sind, so kann man das dritte immer und nur auf eine Weise so bestimmen, dass

$$
a b=c
$$

ist.

$[\ldots]$

Für unendliche Gruppen kann nicht mehr so geschlossen werden [in a footnote Weber gives the example of the positive integers under multiplication]. Für unendliche Gruppen wird also noch die Eigenschaft 4. als Forderung in die Begriffsbestimmung mit aufgenommen.

Where Weber's 1882 definition is written in the effective and ruthless style of a research paper, the 1896 version, although it seems equally clear, is more leisurely and appropriate to its textbook context. Moreover, it has been developed (if perhaps only as an afterthought) to deal explicitly with infinite groups. Axiom 4 looks different from existence of inverses but is superficially equivalent to it and, as a result, what Weber offers is very close to a modern description of what a group is.

Weber's book appears to have been quickly appreciated-for example, the axiomatisation of finite groups that James Pierpont gave in 1900 involves closure (essentially in the form that asks for a binary operation on the set), associativity, existence of identity and existence of inverses [37]. Nevertheless, as has already been observed, it seems to have influenced Burnside rather less than one might have expected. If so then he was not alone. The mathematical encyclopaedia [30] of the time contains extensive references to groups. It has a chapter 'Endliche diskrete Gruppen' by Burkhardt, a chapter 'Endliche Gruppen linearer Substitutionen' by Wiman, and several sections of other chapters, such as the chapter by Hölder on Galois Theory, devoted to groups. Almost all these groups, however, are concrete groups of substitutions of one kind or another. There is just one short section in the chapter by Burkhardt which has something more abstract. It is headed 'Allgemeiner Gruppenbegriff' and defines a group to be an associative system with cancellation. It is true that, immediately after the definition the focus is on finite such systems. Nevertheless, the point of defining a group abstractly and making existence of inverses (as in Dyck's exposition) or solubility of equations (as in Weber's) a requirement had not yet been fully grasped. 


\section{FOCUS ON AXIOMATICS,}

At about this time, however, a new phenomenon emerged, namely, interest in axiomatics as a topic in its own right. Presumably this was inspired by the famous work of Dedekind, C.S. Peirce, Hilbert, Frege, Russell and many others towards the logicisation of mathematics. The papers [23, 24, 32] of Huntington and Moore form a written discussion in 1902 (part of which may, perhaps, have been conducted orally at meetings of the American Mathematical Society) about axiom systems for group theory. They mention Weber's, Burnside's and Pierpont's definitions of what a group is and then exhibit axiom systems of their own. The focus is more in independence of the proposed axioms, however, than in pinning down a precise description of what a group should be.

It was also at about this time, or a year or two later, that the conscious recognition of 'abstractness' of a group became established. The word abstract was used with two meanings. In the writings of L. E. Dickson and others an abstract group was a group described by generators and relations in the manner of Dyck. But in the preface of De Séguier's book [13] published in 1904 the term is explained as follows:

Des divers groupes particuliers rencontrés en Algèbre, en Analyse et en Géométrie devait nécessairement se dégager l'idée du groupe abstrait, c'est-àdire du groupe considérée en lui-même, indépendamment de la nature de ses éléments.

Unfortunately, his definition of a group, which seeks to build on those of Huntington and Moore and pays attention to independence of axioms, is seriously defective in a number of ways. We will, however, not pursue this point here.

Economical axiom systems defining a group as a set $G$ with a binary operation $G \times G \rightarrow G$ satisfying

$$
\forall a, b, c: a(b c)=(a b) c \text { and } \forall a, b \exists x: a x=b \text { and } \forall a, b \exists x: x a=b
$$

or

$$
\forall a, b, c: a(b c)=(a b) c \text { and } \exists e \forall a \exists b: a e=a \& a b=e
$$

or the obvious dual of this in which existence of right identity and right inverses is replaced with existence of left identity and left inverses, are nowadays well-known if not as widely used as the standard textbook definition discussed in the second paragraph of this paper. A careful analysis of such systems is to be found in a paper by Baer and Levi [1] of 1932. About that time it was realised that there is advantage to be gained in the avoidance of existential quantifiers in axioms. Thus if a group is specified as a set $G$ equipped with a binary operation $G \times G \rightarrow G,(a, b) \mapsto a b$, a nullary operation 
$\{\emptyset\} \rightarrow G, \emptyset \mapsto e$, and a unary. operation $G \rightarrow G, a \mapsto a^{-1}$, then the axioms may be expressed in equational form as

$$
\forall a, b, c: a(b c)=(a b) c \text { and } \forall a: a e=e a=a \quad \text { and } \forall a: a a^{-1}=a^{-1} a=e,
$$

or

$$
\forall a, b, c: a(b c)=(a b) c \text { and } \forall a: a e=a \text { and } \forall a: a a^{-1}=e
$$

or

$$
\forall a, b, c: a(b c)=(a b) c \text { and } \forall a: e a=a \text { and } \forall a: a^{-1} a=e
$$

Such systems define the class of groups by means of identities and exhibit the class of all groups as a variety (see Birkhoff [2], Neumann [33]). And of course this is the context of the papers $[21,34]$ and $[35]$.

\section{A POSTSCRIPT}

The introductory section of this paper contains comments on a textbook exposition of the axioms of group theory. One of those comments is addressed to the notion of Closure. In a letter to me dated 21st February 1999 Walter Ledermann, author of the highly successful textbook [29] (not the course cited in my introduction), discussed terminology (in relation to Burnside's usage of 'self-conjugate' where we now use 'normal') and then wrote:

It may be difficult to find the right word. When my Introduction to the theory of finite groups appeared in 1949 I gave a complimentary copy to $H$. W. Turnbull, who had been my revered mentor and fatherly friend at St. Andrews. Turnbull was an eminent member of the Cambridge school of classical algebraists and had taken little interest in group theory or abstract algebra. A few days after I had given him the book he said to me: "I have looked at your little book on group theory. On page 2 you state that a group is a set that is closed with respect to multiplication." Always eager to correct my foreign lapses in English he added benevolently: "Surely, Walter, what you wanted to say is the set is open to multiplication."

ACKNOWLEDGEMENTS: It is a pleasure to acknowledge my gratitude to Emeritus Professor Walter Ledermann for permission to include the above passage from his letter and to thank my wife Sylvia who read a draft of this paper with a helpfully critical eye.

\section{REFERENCES}

[1] R. Baer and F. Levi, 'Vollständige irreduzible Systeme von Gruppenaxiomen', Sitzungsber. Akad. Wiss. Heidelberg, 2 (1932), 1-12. 
[2] G. Birkhoff, 'On the structure of abstract algebras', Proc. Cambridge Philos. Soc., 31 (1935), 433-454.

[3] R.A. Bryce, 'Ruffini and the quintic equation', Symposia Mathematica 27 (Cortona, 1983), 169-185.

[4] Heinrich Burkhardt, 'Die Anfänge der Gruppentheorie und Paolo Ruffini', Zeitschr. für Math. und Phys., 37 (1892), Supplement, pp. 119-159.

[5] W. Burnside, 'Notes on the theory of groups of finite order', Proc. London Math. Soc., 26 (1895), 191-214.

[6] W. Burnside, Theory of groups of finite order. (C.U.P., Cambridge 1897). (Second edition, Cambridge 1911; reprint: Dover Publications, New York 1955).

[7] Jean Cassinet, 'Paolo Ruffini (1765-1822): la résolution algébrique des équations et les groupes de permutations', Boll. Storia Sci. Mat., 8 (1988), 21-69.

[8] Augustin Cauchy, 'Sur le nombre des valeurs égales ou inégales que peut acquérir une fonction de $n$ variables indépendantes, quand on y permute ces variables entre elles d'une manière quelconque', C. R. Acad. Sci. Paris, 21 (1845), 593-607 (15 Sept.) = Euvres, 1st series, IX, 277-293.

[9] Augustin Cauchy, 'Mémoire sur les arrangements que l'on peut former avec des lettres données et sur les permutations ou substitutions à l'aide desquelles on passe d'un arrangement à un autre', Exercices d'analyse et de physique mathématique, Vol III (dated Paris 1844: in fact published in 'livraisons' from 1844 to 1846), pp. 151-252 = Euvres, 2nd series, XIII, 171-282.

[10] A. Cayley, 'On the theory of groups, as depending on the symbolic equation $\theta^{n}=1$ ', Phil. Mag., VII (1854), 40-47 = Mathematical Papers, Cambridge 1889-1898, Vol.II, Paper 125, pp. 123-130.

[11] A. Cayley, 'On the theory of groups', Proc. London Math. Soc., 9 (1878), 126-133= Mathematical Papers, Vol. X, Paper 690, pp. 324-330.

[12] A. Cayley, 'Desiderata and suggestions: (1) The theory of groups', Amer. J. Math., 1 (1878), 50-52 = Mathematical Papers, Vol. X, Paper 694, pp. 401-403.

[13] J.-A. De Séguier, Théorie des groupes finis: Éléments de la théorie des groupes abstraits. (Gauthier-Villars, Paris, 1904).

[14] Walther Dyck, 'Gruppentheoretische Studien', Math. Annalen, 20 (1882), 1-44.

[15] Walther Dyck, 'Gruppentheoretische Studien, II: Ueber die Zusammensetzung einer Gruppe discreter Operationen, über ihre Primitivität und Transitivität', Math. Annalen, 22 (1883), 70-108.

[16] Harold M. Edwards, Galois theory. (Springer-Verlag, Berlin, Heidelberg, New York, 1984).

[17] G. Frobenius, 'Neuer Beweis des Sylowschen Satzes', J. f. d. reine u. angew. Math. (Crelle), 100 (1887), 179-181 = Gesammelte Abhandlungen (J.P. Serre, Editor) (SpringerVerlag, Berlin, Heidelberg, New York 1968), Vol. II, 301-303.

[18] G. Frobenius and L. Stickelberger, 'Über Gruppen von vertauschbaren Elementen', $J$. $f$. d. reine u. angew. Math. (Crelle's Journal), 86 (1879), 217-262 = Gesammelte Abhandlungen, Vol. I, 545-590. 
[19] Évariste Galois, 'CEuvres mathématiques' (edited by J. Liouville), J. de math. pures et appl. (Liouville's Journal), 11 (1846), 381-444.

[20] Évariste Galois, Écrits et mémoires mathématiques d'Évariste Galois. (Robert Bourgne and J.-P. Azra, Editors) (Gauthier-Villars, Paris, 1962); reprinted with small alterations 1977.

[21] Graham Higman and B.H. Neumann, 'Groups as groupoids with one law', Publ. Mathematicae, 2 (1952), 215-221 = Selected works of B.H. Neumann and Hanna Neumann (6 volumes edited by D. S. Meek and R.G. Stanton), (Charles Babbage Research Centre, Winnipeg, 1988) Vol. 5, 1069-1075.

[22] O. Hölder, 'Zurückführung einer beliebigen algebraischen Gleichung auf eine Kette von Gleichungen', Math. Annalen, 34 (1889), 26-56.

[23] E.V. Huntington, 'Simplified definition of a group', Bull. Amer. Math. Soc., 8 (1902), 296-300.

[24] E.V. Huntington, 'A second definition of a group', Bull. Amer. Math. Soc., 8 (1902), 388-391.

[25] Camille Jordan, Traité des substitutions et des équations algébriques. (Gauthier-Villars, Paris, 1870) (reprints: Blanchard, Paris 1957; Gabay, Sceaux 1992).

[26] Camille Jordan, Euvres (4 volumes edited by Jean Dieudonné), (Gauthier-Villars, Paris, 1961).

[27] Felix Klein, 'Vergleichende Betrachtungen über neuere geometrische Forschungen' (The Erlanger Programm) in Gesammelte mathematische Abhandlungen (edited by R. Fricke and A. Ostrowski), (Springer, Berlin, 1921) Vol 1, pp. 460-497.

[28] L. Kronecker, 'Auseinandersetzung einiger Eigenschaften der Klassenanzahl idealer complexer Zahlen', Monatsber. Kön. Preuss. Akad. Wiss., Berlin, (1870), 881-889= Leopold Kronecker's Werke (K. Hensel, Editor), Leipzig 1895 (reprint: Chelsea company, New York 1968), Vol. I, pp. 273-282.

[29] Walter Ledermann, Introduction to the theory of finite groups. (Oliver and Boyd, Edinburgh, 1949).

[30] Wilhelm Franz Meyer (editor), Encyklopädie der mathematischen Wissenschaften mit Einschluss ihrer Anwendungen. Erster Band: Arithmetik und Algebra. (Teubner, Leipzig, 1898-1904).

[31] George Abram Miller, Collected works, Vol. 1 (University of Illinois, 1935).

[32] Eliakim Hastings Moore, 'A definition of abstract groups', Trans. Amer. Math. Soc., 3 (1902), 485-492.

[33] B.H. Neumann, 'Identical relations in groups', Math. Annalen, 114 (1937), 506-525 = Selected works of B.H. Neumann and Hanna Neumann (6 volumes edited by D.S. Meek and R.G. Stanton) (Charles Babbage Research Centre, Winnipeg, 1988) Vol. 1, 151-170.

[34] B.H. Neumann, 'Another single law for groups', Bull. Australian Math. Soc., 23 (1981), 81-102 = Selected works, Vol. 5, 1076-1097.

[35] B.H. Neumann, 'Yet another single law for groups', Illinois J. Maths, 30 (1986), 295-300 $=$ Selected works, Vol. 5, 1098-1103. 
[36] Peter M. Neumann, 'The context of Burnside's contributions to group theory', The collected papers of William Burnside (2 volumes edited by A.J.S. Mann, Peter M. Neumann and J.C. Tompson) (Clarendon Press, Oxford) to appear.

[37] James Pierpont, 'Galois theory of algebraic equations. Part II. Irrational resolvents', $A n$ nals of Math. (Series 2), 2 (1900-1901), 22-56.

[38] J.-A. Serret, Cours d'Algèbre Supérieure. Third edition: 2 Vols (Gauthier-Villars, Paris, 1866).

[39] René Taton, 'Sur les relations scientifiques d'Augustin Cauchy et d'Évariste Galois', Revue d'histoire des sciences, 24 (1971), 123-148.

[40] H. Weber, 'Beweis des Satzes, dass jede eigentlich primitive quadratische Form unendlich viele Primzahlen darzustellen fähig ist', Math. Annalen, 20 (1882), 301-329.

[41] Heinrich Weber, Lehrbuch der Algebra. Vieweg und Sohn, Braunschweig: First edition (2 vols), 1895, 1896; Second edition: 2 vols and a third volume on elliptic functions, 1898, $1899,1908$.

[42] Hans Wussing, Die Genesis des abstrakten Gruppenbegriffes. (Deutsche Verlag der Wissenschaften, Berlin 1969). English translation by Abe Schenitzer, The genesis of the $a b$ stract group concept (MIT Press, 1984).

The Queen's College

Oxford OX1 4AW

United Kingdom 